\title{
Monitoring of high-flow nasal cannula for SARS-CoV-2 severe pneumonia: less is more, better look at respiratory rate
}

\author{
Damien Blez ${ }^{1}$, Anne Soulier ${ }^{1}$, Francis Bonnet ${ }^{1}$, Etienne Gayat ${ }^{2}$ and Marc Garnier ${ }^{1 *}$ (i)
}

๑) 2020 Springer-Verlag GmbH Germany, part of Springer Nature

\section{Dear Editor,}

The main clinical features of severe Corona Virus Disease 2019 (COVID-19) are hypoxaemia and respiratory failure [1]. Some COVID-19 patients may benefit from high-flow oxygen through nasal cannula (HFNC) [2]. However, it is critical not to delay intubation when it becomes necessary, otherwise increased mortality may be observed [3]. The "ROX index", dividing the oxygen saturation by the inspired oxygen fraction and the respiratory rate $\left(\mathrm{SpO}_{2} / \mathrm{FiO}_{2} / \mathrm{RR}\right)$, has been proposed to monitor patients treated with $\operatorname{HFNC}[4,5]$.

We conducted a monocentric prospective observational study to assess the accuracy of several parameters, including the ROX, to detect HFNC failure in the specific setting of SARS-CoV-2-related severe pneumonia. All the patients admitted in our intensive care unit with proven COVID-19 requiring HFNC during March and April 2020 were included. Clinical parameters were collected within the $4 \mathrm{~h}$ before, and $30 \mathrm{~min}, 2$ and $6 \mathrm{~h}$ after HFNC initiation. HFNC was systematically initiated at 60 $\mathrm{L} \min ^{-1} / \mathrm{FiO}_{2} 1$. Then, $\mathrm{FiO}_{2}$ was decreased hourly, maintaining $92 \% \leq \mathrm{SpO}_{2} \leq 98 \%$, down to 0.4 , at which point flow was progressively reduced until weaning. "HFNC failure" was defined as the need for invasive mechanical ventilation within 7 days of HFNC onset.

Thirty patients were included (Table S1 in the eSupplement). Prior to HFNC, the median [IQR] RR was 30 $[26-36] / \mathrm{min}$ and $\mathrm{O}_{2}$ flow was $10[8-15] \mathrm{L} / \mathrm{min}$. Sixteen

\footnotetext{
${ }^{*}$ Correspondence: marc.garnier@aphp.fr

1 GRC 29, APHP.6, DMU DREAM, Anesthesiology and Critical Care

Department, Saint-Antoine Hospital, Sorbonne University, 184 rue du Faubourg Saint-Antoine, 75012 Paris, France

Full author information is available at the end of the article
}

patients met the outcome "HFNC failure" after 1 [0.92.5] day. The remaining 14 patients were weaned after 5 [4-7] days. Although not different before HFNC onset, RR was significantly lower at H0.5 in the "weaned" compared to the "failure" group (24 [20-24] vs. 31 [27-34]/ min, $p=0.004)$. The area under the receiver operating characteristic curve (AUROC) of RR at H0.5 was 0.81 95\% CI [0.61-0.96] (Fig. 1), with a best cut-off value at $26 /$ min (sensitivity $75 \%$, specificity $85 \%$, positive likelihood ratio 4.9). $\mathrm{RR}$ at $\mathrm{H} 2$ and $\mathrm{H} 6$ was less informative (Table S2). ROX H0.5 had an AUROC of 0.78 [0.58-0.95]. Performance characteristics of ROX H0.5 using the previous published cut-off value of $4.88[4,5]$ were $81 \%$ sensitivity, $38 \%$ specificity and a positive likelihood ratio of 1.3. Neither the ROX at $\mathrm{H} 2$ and H6, nor its changes between $\mathrm{HO}$ and $\mathrm{H} 0.5, \mathrm{H} 0.5-\mathrm{H} 2$, and $\mathrm{H} 2-\mathrm{H} 6$, had better diagnostic performance than RR at H0.5 (Tables S1 and S2). Results for the other parameters are reported in Fig. 1 and in the eSupplement.

The main limitations of this derivation cohort are its monocentric design and the small number of patients included. These results should be confirmed in future validation cohorts before proposing to intubate patients who are still very tachypneic as early as $30 \mathrm{~min}$ after HFNC onset. However, our results suggest that monitoring COVID-19 patients requiring HFNC with the ROX index did not add value to $R R$ alone. This is in agreement with a possible lower diagnostic value of the ROX in viral pneumonia [4]. This may be because the ROX was mostly dependent on $\mathrm{RR}$, as $\mathrm{FiO}_{2}$ was persistently high during the first hours of HFNC [6] and as COVID19 patients may present higher dead space due to diffuse pulmonary thrombi [7]. In addition, one-third of the patients had $100 \% \mathrm{SpO}_{2}$ despite the $92 \% \leq \mathrm{SpO}_{2} \leq 98 \%$

\section{Springer}




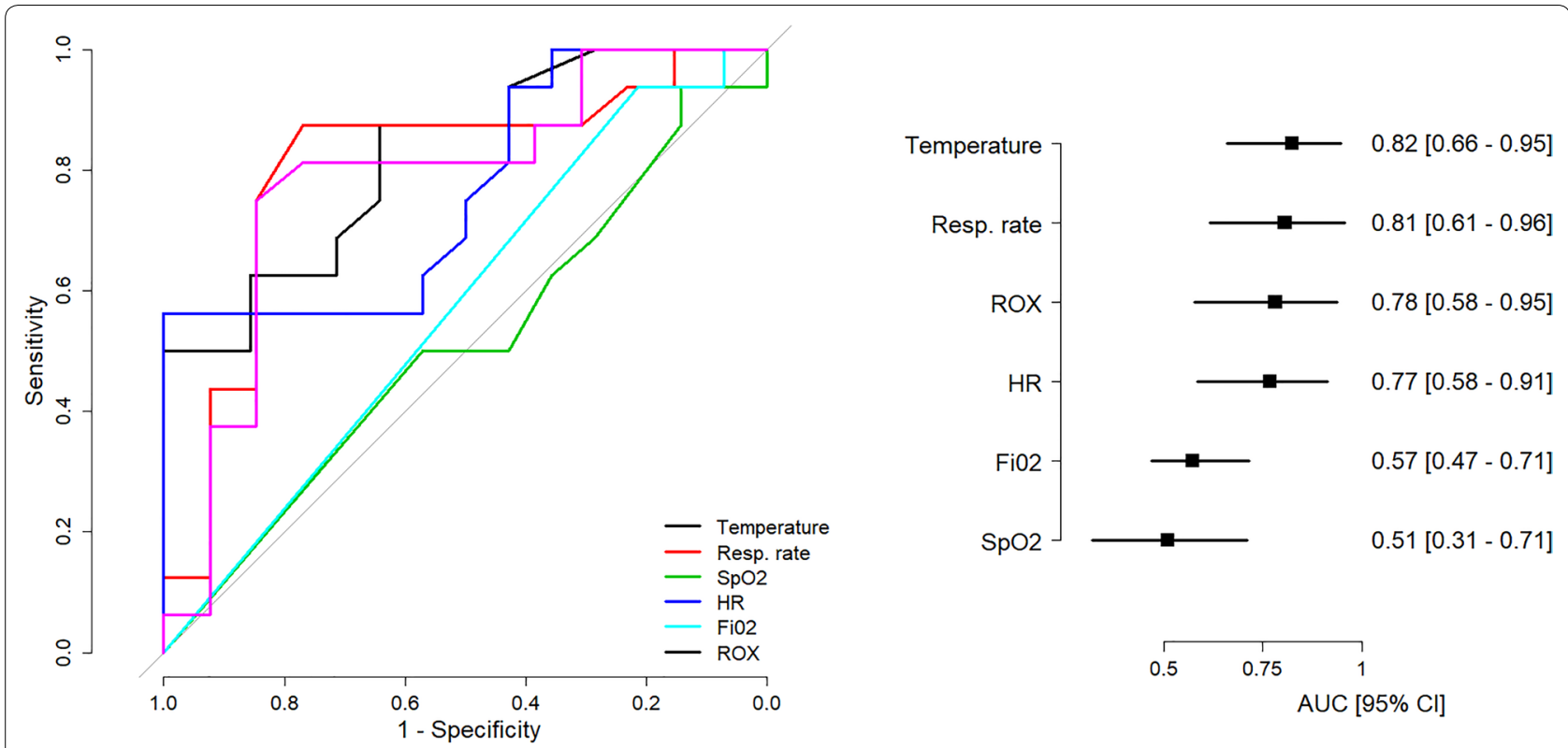

Fig. 1 Receiver Operating Characteristic (ROC) curves for the principal clinical parameters for the diagnosis of high-flow nasal cannula failure. SpO oxygen saturation, $\mathrm{HR}$ heart rate, $\mathrm{FiO}_{2}$ inspired oxygen fraction, $\mathrm{ROX}$ "Respiratory rate-Oxygenation" index

target, which may have decreased the contribution of the $\mathrm{SpO}_{2} / \mathrm{FiO}_{2}$ in the diagnostic accuracy of the ROX. Our results highlight the need for continuous monitoring of COVID-19 patients requiring HFNC, and suggested reinforcing the surveillance of patients with a $\mathrm{RR} \geq 26 / \mathrm{min}$ half an hour after HFNC onset, as it may be associated with a high risk of intubation.

In conclusion, among the respiratory parameters available for monitoring COVID-19 patients treated with HFNC, using the RR is accurate and simple, thus "being most likely the right solution" according to Occam's razor.

Electronic supplementary material

The online version of this article (https://doi.org/10.1007/s00134-020-06199-9) contains supplementary material, which is available to authorized users.

\section{Author details}

${ }^{1}$ GRC 29, APHP.6, DMU DREAM, Anesthesiology and Critical Care Department, Saint-Antoine Hospital, Sorbonne University, 184 rue du Faubourg Saint-Antoine, 75012 Paris, France. ${ }^{2}$ APHP.7, DMU PARABOL, Anesthesiology and Intensive Care Department, Lariboisière Hospital, Paris University, Paris, France.

\section{Funding}

This work has not been funded by any external source.

\section{Availability of data and material}

Data are available from the corresponding author on reasonable request.

\section{Compliance with ethical standards}

\section{Conflicts of interest}

All the authors declare that they do not have any competing interest with the current work.

\section{Ethics approval}

This work has been approved by the French Anesthesiology and Intensive Care Medicine Society (SFAR) ethical committee (IRB 00010254-2020-096).

\section{Publisher's Note}

Springer Nature remains neutral with regard to jurisdictional claims in published maps and institutional affiliations.

Accepted: 24 July 2020

Published online: 31 July 2020

\section{References}

1. Wu Z, McGoogan JM (2020) Characteristics of and important lessons from the Coronavirus disease 2019 (COVID-19) outbreak in China : summary of a report of 72314 cases from the Chinese center of disease control and prevention. JAMA 323(13):1239-1242

2. Wang K, Zhao W, Li J, Shu W, Duan J (2020) The experience of high-flow nasal cannula in hospitalized patients with 2019 novel coronavirus-infected pneumonia in two hospitals of Chongqing, China. Ann Intensive Care 10(1):37

3. Kang BJ, Koh Y, Lim C-M, Huh JW, Baek S, Han M et al (2015) Failure of highflow nasal cannula therapy may delay intubation and increase mortality. Intensive Care Med 41(4):623-632

4. Roca O, Messika J, Caralt B, García-de-Acilu M, Sztrymf B, Ricard J-D et al (2016) Predicting success of high-flow nasal cannula in pneumonia patients with hypoxemic respiratory failure: the utility of the ROX index. J Crit Care 35:200-205

5. Roca O, Caralt B, Messika J, Samper M, Sztrymf B, Hernandez G et al (2019) An index combining respiratory rate and oxygenation to predict outcome of nasal high-flow therapy. Am J Respir Crit Care Med 199(11):1368-1376

6. Tatkov S (2019 Jul 1) Nasal high-flow therapy: role of $\mathrm{FiO}_{2}$ in the ROX index. Am J Respir Crit Care Med 200(1):115-116

7. Poor HD, Ventetuolo CE, Tolbert T, Chun G, Serrao G, Zeidman A et al (2020) COVID-19 critical illness pathophysiology driven by diffuse pulmonary thrombi and pulmonary endothelial dysfunction responsive to thrombolysis. Clin Transl Med. https://doi.org/10.1002/ctm2.44 